\title{
O PROTAGONISMO DO COORDENADOR PEDAGÓGICO NA FORMAÇÃO DOCENTE: experiência na Educação Infantil em Ji- Paraná-RO
}

\author{
Helen Maciel da Silva? \\ Ednéia Maria Azevedo Machado² \\ Juracy Machado Pacífico ${ }^{3}$
}

\section{RESUMO}

O estudo é resultado de observações feitas ao longo da execução do projeto de extensão da Universidade Federal de Rondônia em parceria com o município de JiParaná/RO, no período de 2015 a 2017. Apresenta uma reflexão sobre o processo e o impacto dos resultados da formação continuada realizada com coordenadores pedagógicos e professores que atuam na Educação Infantil no Município de JiParaná-RO. A metodologia utilizada foi análise dos registros dos encontros de formação, a avaliação final, bem como a observação da participação e dos relatos feitos pelas coordenadoras no espaço de formação. Os sujeitos da pesquisa foram quatorze coordenadoras pedagógicas que atuam na rede municipal. Utilizou-se como referencial teórico as contribuições de Alarcão (2001), Scarpa (1998), Hoffmann (2012), entre outros. Destaca a importância da implementação de um projeto de formação específico para os profissionais da Educação Infantil, bem como discute os caminhos percorridos neste processo no município de JiParaná/RO. Os resultados apontam que a formação continuada para o coordenador pedagógico é de extrema importância, pois ele é o profissional responsável pela formação continuada dos professores no espaço escolar, bem como aquele que possibilita a qualidade das atividades pedagógicas.

Palavras-chave: Coordenador Pedagógico. Formação. Educação Infantil.

\footnotetext{
1 Mestranda no Programa de Pós-Graduação em Educação Escolar, Mestrado Profissional (MEPE/2016) da Fundação Universidade Federal de Rondônia. E-mail: helen2maciel@gmail.com

2 Mestre em educação (UFMS/2007), Professora efetiva na Fundação Universidade Federal de Rondônia, curso de Licenciatura em Pedagogia. E-mail: volneyedneia@hotmail.com

3 Doutora em educação (UNESP/2010), Professora Associada da Fundação Universidade Federal de Rondônia, curso de Licenciatura em Pedagogia e do Programa de PósGraduação em Educação Escolar, Mestrado Profissional (PPGEE/MEPE). E-mail: juracypacifico@unir.br
} 


\title{
THE PROTAGONISM OF THE PEDAGOGICAL COORDINATOR IN TEACHER
}

\author{
EDUCATION: experience in Early Childhood Education in Ji-Paraná-RO
}

\begin{abstract}
The study is the result of observations made during the execution of the extension project of the Federal University of Rondônia in partnership with the municipality of JiParaná / RO, from 2015 to 2017. It presents a reflection on the process and the impact of the results of the continuing education course taken by pedagogical coordinators and teachers involved in Early Childhood Education in the Municipality of Ji-Paraná-RO. The methodology used was the analysis of the records of the meetings with the teachers, the final evaluation, as well as the observation of the participation and the reports made by the coordinators during the sessions. The research subjects were fourteen pedagogical coordinators who work in schools of the municipality. The contributions of Alarcão (2001), Scarpa (1998), Hoffmann (2012) and others were used as theoretical reference. It highlights the importance of the implementation of a specific teacher education project for professionals engaged in Early Childhood Education, and it discusses the paths covered in this process in the municipality of Ji-Paraná / RO. The results indicate that continuing education for pedagogical coordinators is extremely important since they are the professionals responsible for delivering continuing teacher education and providing guidance for high-quality pedagogical activities in their schools.
\end{abstract}

Keywords: Pedagogical Coordinator. Education. Early Childhood Education.

\section{EL PROTAGONISMO DEL COORDINADOR PEDAGÓGICO EN LA FORMACIÓN}

\author{
DOCENTE: Experiencia en la Educación Infantil en Ji-Paraná-RO
}

\section{RESUMEN}

El estudio es el resultado de las observaciones realizadas a lo largo de la ejecución del proyecto de extensión de la Universidad Federal de Rondonia en convenio con el municipio de Ji-Paraná/RO. Se presenta una reflexión sobre el processo y el impacto de los resultados de la formación continuada realizada con Coordinadores Pedagógicos y Profesores que actuan en la Educación Infantil en el Municipio de JiParaná-RO en el período 2014 a 2017. Una metodología utilizada fue el registro de los encuentros de formación, la evaluación final, como también la observación de la participación y de los relatos hechos por las coordinadoras en el espacio de la formación-. Los sujetos de de la investigación fueron catorce Coordinadoras $s$ Pedagógicas que actúan em la red municipal. Se utilizo como referencial teórico las contribuciones Alarcão (2001), Scarpa (1998), Hoffmann (2012) entre otros. Se destaca la importancia de implementación de un proyecto de formación específica para los profesionales de la Educación Infantil, también como la discusión de los recorridos en este proceso en el municipio de Ji-Paraná / RO. Los resultados apuntam que la formación continuada para el Coordenador Pedagógico es de extrema importancia, pues es este el profesional responsable por la formacióno continuada de los profesores en el espacio de los escolar, asimismo como aquel que posibilita la calidad de las atividades pedagógicas.

Palabras clave: Coordinador Pedagógico. Entrenamiento. Educación Infantil. 


\section{INTRODUÇÃO}

Este texto é resultado das reflexões feitas a partir das ações desenvolvidas no projeto "A Formação das Coordenadoras Pedagógicas da Educação Infantil", que se caracterizou como um trabalho de extensão do Departamento de Educação - Curso de Pedagogia, do Campus de JiParaná vinculado ao Grupo de Pesquisa em Educação na Amazônia - GPEA, em parceria com o município de Ji-Paraná no ano de 2015 à 2017 e teve como objetivo oferecer formação continuada para as coordenadoras pedagógicas das escolas de Educação Infantil da rede municipal e teve como questão fundamental a formação continuada dos profissionais da Educação Infantil, por meio das ações das coordenadoras pedagógicas.

A rede municipal atualmente conta com 11 (onze) Centros Municipais de Educação Infantil, os quais atendem creche e pré-escola, uma instituição conveniada, duas escolas de Ensino Fundamental, que oferece turmas de pré-escola localizadas na área urbana, e cinco escolas de Ensino Fundamental localizadas na área rural que oferecem o atendimento para turmas de pré-escola, totalizando 19 instituições que atendem a educação infantil.

A inclusão de Creches e Pré-Escolas no sistema educacional significou pensar a Educação Infantil numa perspectiva mais ampla e complexa motivando profundas discussões em relação à finalidade desta etapa da educação básica. Ao distanciar-se das característas de espaços voltados ao assistencialismo para serem pensados de forma educacional, considerando os eixos norteadores interações e brincadeiras, o cuidar e o educar de forma indissociáveis, as instituições de Educação Infantil têm suscitado muitas reflexões e enfrentado muitos desafios que vêm sendo discutidos no campo educacional: como pensar a práticas educacional para crianças de o a 5 anos de idade considerando as especificidades desse período da vida do ser humano? Como planejar considerando as experiênciasdessas crianças tão pequenas? Que concepções de criança e infância são reveladas na prática pedagógica da forma como é desenvolvida no cotidianamente? 
Além destes questionamentos, esbarra-se na formação dos profissionais que atendem essas crianças, pois para essa abordagem educativa, já não basta "gostar de criança", ser meiga e carinhosa. Isso é importante, mas não é tudo.

Diante de tais dilemas pedagógicos, o projeto de formação objetivou investigar as concepções e práticas pedagógicas presentes e desenvolvidas na educação infantil, e promover estudos de formação continuada com os coordenadores pedagógicos na perspectiva de que estes pudessem estender essa formação aos docentes, formando então uma rede de formação pensada especificamente para profissionais que atuam nessa primeira etapa da educação básica.

Neste contexto, consideramos o coordenador, profissional responsável diretamente pela formação dos professores em serviço, e que tem como objetivo a busca pela qualidade da educação oferecida para as crianças na primeira infância, conforme afirmam Abreu e Bruno.

Um profissional que na unidade escolar responde fundamentalmente pelo processo de formação continuada dos educadores e pelo projeto de construção da relação entre teoria e docentes. É o mediador que articula a construção coletiva do projeto político pedagógico da escola e que, em comunhão com os professores, elabora a qualidade das práticas educativas, favorecendo também, nesse processo, o crescimento intelectual, afetivo e ético de educadores e alunos (ABREU; BRUNO, 2006, p. 105).

Sendo a educação infantil uma etapa de ensino que exige profissionais cada vez mais capacitados para lidar com as especificidades das crianças atendidas nessa faixa etária, os profissionais precisam de tempo dedicado a estudos para que seja possível a reflexão sobre a prática. Assim, justifica-se um projeto de formação específico para o coordenador pedagógico entendido aqui como o profissional corresponsável pela aprendizagem e desenvolvimento das crianças e aquele que proporciona a formação continuada para seu grupo de docentes.

A opção por usar o termo coordenador pedagógico se dá em função do projeto de extensão que utiliza essa terminologia. Porém, no município parceiro esse profissional é denominado supervisor escolar. Destaca-se que 
no decorrer das leituras realizadas encontrou-se expressões como supervisão, supervisão educacional, supervisão escolar, supervisão pedagógica, coordenação, coordenação pedagógica e coordenação de área ou disciplina. São, portanto, várias as terminologias para um profissional que desempenha a mesma função.

Os estudos desenvolvidos são apresentados neste texto da seguinte forma: no primeiro momento apresenta-se uma abordagem teórica acerca do papel do coordenador pedagógico e a formação continuada em serviço. Em segundo momento é contextualizado o desenvolvimento do projeto e os caminhos percorridos para a consolidação das ações desenvolvidas. Por último, apresentamos a análise a partir dos dados coletados, bem como as contribuições deste projeto de formação para as mudanças na prática das coordenadoras pedagógicas, na concepção e prática de professores e no cotidiano das escolas da educação infantil do município de Ji-Paraná.

\section{COORDENADORAS PEDAGÓGICAS COMO ARTICULADORAS DA FORMAÇÃO EM SERVIÇO}

A história de atuação do coordenador pedagógico é marcada no Brasil por um ranço daquele profissional fiscalizador, burocrático, que não reconhece que cumpre uma função política, tampouco que função é essa, e menos ainda sabe explicitá-la (SAVIANI, 2010). Essa característica ainda se revela na prática de muitos coordenadores na rede pesquisada.

Uma das primeiras ações do projeto desenvolvida foi entender qual a compreensão das coordenadoras pedagógicas em relação ao seu papel dentro da escola. Ao realizarmos rodas de conversas e análise de registro das reuniões realizadas por essas profissionais, percebemos que suas práticas estavam pautadas em questões administrativas, não havendo uma separação do que era administrativo e o que eram pautas pedagógicas com foco na formação continuada. Diante deste contexto um dos objetivos da formação foi proporcionar momentos de reflexões e estudos sobre o papel do coordenador e sua função como formador de sua equipe, ou seja, 
colocar a formação no centro de suas ações. Assim, conforme Ferreira (2012):

Ora, se compreendo a supervisão como um importante elemento integrante da gestão da educação, responsável pela garantia da qualidade do processo educacional que ocorre na escola e no sistema, coloca-se imperiosamente a formação como centro do trabalho da supervisão educacional. A formação é a categoria principal do nosso raciocínio e de nossa existência de educadores para a qual trabalhamos profissionalmente (p. 112).

Deste modo, entende-se o papel do coordenador pedagógico como o gestor do currículo escolar, com o compromisso de ser educador junto aos professores e que sua ação formativa junto aos docentes considere as vivências e práticas da escola, que estas sejam objeto de reflexão e pesquisa, com o objetivo de redimensionamento quando se fizer necessário, mas isto não é tarefa fácil, nem simples:

\begin{abstract}
Mudar prática significa reconhecer limites e deficiências no próprio trabalho. Significa lançar olhares questionadores e de estranhamento para práticas que nos são tão familiares que parecem verdadeiras, evidentes ou impossíveis de serem modificadas. Significa alterar valores e hábitos que caracterizam de tal modo nossas ações e atitudes que constituem parte de nossa identidade pessoal e profissional. Mudar prática implica o enfrentamento inevitável e delicado de conflitos entre os participantes (professores, alunos, pais e a hierarquia do sistema escolar), originados de visões de mundo, valores, expectativas e interesses diferentes. Mudar práticas implica mudanças na forma de relacionamento entre participantes, e isso pode gerar desestabilidade na estrutura de poder, riscos de novos conflitos, desgastes e frustações para a comunidade escolar. Mudar prática pedagógica significa empreender mudanças em toda cultura organizacional (PIMENTA, 2007, p. 10).
\end{abstract}

O projeto configurou-se como um chamamento para que cada coordenadora pudesse olhar para a própria prática, refletir seu papel enquanto gestora do currículo e principalmente seu papel de formadora, compreendendo que o processo é doloroso, mas necessário e eficaz para a formação continuada.

No município de Ji-Paraná/RO, as coordenadoras pedagógicas são as profissionais que atuam diretamente com os professores e uma de suas atividades é a atuação direta na formação continuada dos docentes no ambiente de trabalho. Por este motivo, tem elementos e condições de 
atender um maior número de professores e estabelecer instâncias formativas a partir de suas experiências, contribuindo de forma efetiva com a prática pedagógica do docente da Educação Infantil. Por isso, podemos dizer que a coordenadora pedagógica é uma das profissionais mais estratégicas na formação continuada da equipe de professores e na construção de um trabalho pedagógico que considere a infância e as crianças nas escolas de Educação Infantil. Nesse sentido, Zeichner (1998) alerta para a importância do espaço escolar ser fonte permanente de pesquisa:

\begin{abstract}
A formação do professor deve ser pensada em um coletivo que se proponha a assumir o protagonismo das suas ações, pela via da pesquisa da/na própria prática; a ideia do professor pesquisador ganha contornos nesses contextos, pois permite uma maior aproximação com as atividades não só de ensino e transmissão de conhecimentos, mas, sobretudo, de produção de saberes da/na prática (p. 11).
\end{abstract}

Entender o espaço escolar como fonte de pesquisa permite aos profissionais a reflexão e produção de conhecimentos pautados em suas ações pedagógicas, desenvolvendo sua autonomia e é este professor reflexivo e pesquisador que se pretende formar.

O Referencial Curricular para Educação Infantil (RECNEI) (BRASIL, 1998), e as Diretrizes Curriculares Nacionais para Educação Infantil (DCNEI) (BRASIL, 2009), apontam para a necessidade de uma organização e redirecionamento para o atendimento na Educação Infantil, levando em consideração as especificidades dessa faixa etária. Pautam ainda sobre a formação dos professores, as questões de ordem pedagógica e a organização dos espaços físicos e materiais que fazem parte de um conjunto de aspectos que contribuem de forma efetiva para a qualidade do atendimento.

O trabalho direto com crianças pequenas exige que o professor tenha uma competência polivalente. Ser polivalente significa que ao professor cabe trabalhar com conteúdos de naturezas diversas que abrangem desde cuidados básicos essenciais até conhecimentos específicos provenientes das diversas áreas do conhecimento. Este caráter polivalente demanda, por sua vez, uma formação bastante ampla do profissional que deve tornar-se, ele também, um aprendiz, refletindo constantemente sobre sua prática, debatendo com seus pares, dialogando com as famílias e a comunidade e buscando 
informações necessárias para o trabalho que desenvolve. São instrumentos essenciais para a reflexão sobre a prática direta com as crianças a observação, o registro, o planejamento e a avaliação (BRASIL, 1998, p. 41).

É nesse sentido, que a formação continuada dos professores que atuam nessa etapa educacional merece destaque especial por se tratar de um trabalho realizado com crianças em uma faixa etária que, como sabemos, possui especificidades e necessidades próprias da idade. Então, a formação dos professores da Educação Infantil hoje é um direito dos próprios professores e também das crianças, e o coordenador pedagógico deve desempenhar esse papel fundamental, que é o de articulador constante desse processo formativo, na própria escola.

Corroboramos com Alarcão (2001, p. 19), quando afirma que: "A Escola inovadora é aquela que tem a força de se pensar a partir de si própria". Com isso, o desafio do coordenador pedagógico é envolver os professores nessa tarefa de olhar para suas próprias práticas pedagógicas, enxergar os erros e acertos, discutir e estudar os documentos orientadores a fim de encontrar respostas, e nesse movimento, promover a formação continuada com o coletivo escolar. Isso só é possível quando o coordenador pedagógico tem elementos fortes para essa articulação, por esse motivo acreditamos na importância desta formação in loco para este profissional.

\section{OS CAMINHOS DE UM PROJETO DE FORMAÇÃO}

Ao analisar algumas legislações como a Lei de Diretrizes e Bases da Educação de 1996, que considera a Educação Infantil como a primeira etapa da Educação Básica, a Emenda Constitucional 59 de 11 de setembro de 2009, que torna obrigatória a matricula dos quatro aos 17 anos, o Plano Nacional de Educação (2014) que em sua meta 01 prevê a universalização da pré-escola para crianças de quatro e cinco anos e ampliação para 50\% das crianças de zero a três anos de idade e, o mais recente instrumento legal, a Lei $n^{\circ} 13.257$, de 8 de março de 2016, que dispõe sobre as políticas públicas para a primeira infância, é possível perceber os avanços na 
politicas públicas para as crianças, no que diz respeito à garantia de acesso à Educação Infantil.

Neste contexto, ao lançar o olhar sobre como esse atendimento se efetiva no cotidiano das escolas de Educação Infantil, mesmo com a existência de documentos orientadores da Prática Pedagógica como o Referencial Nacional para a Educação Infantil (BRASIL, 1998), as Diretrizes Nacionais para a Educação Infantil (BRASIL, 2009), é possível constatar que além dos documentos legais e organizacionais, ainda são necessários outros aspectos fundamentais para garantir a qualidade nesta etapa da Educação Básica. Conforme afirma Zabalza (1998),

A qualidade, pelo menos no que se refere às escolas, não é tanto um repertório de traços que se possuem, mais sim algo que vai sendo alcançado. A qualidade é algo dinâmico (por isso faz-se mais alusão às condições culturais das escolas do que aos seus elementos estruturais), algo que se constrói dia a dia e de maneira permanente (ZABALZA, 1998, p. 32).

Desta forma, acreditamos que uma das ações necessárias é a formação continuada dos educadores, mas sabemos que esta representa apenas um dos aspectos que garante a qualidade. Nesse sentido, a formação foi o foco do nosso projeto, que teve início no ano de 2013 em parceria entre o município de Ji-Paraná e a Universidade Federal de Rondônia objetivando a formação continuada dos coordenadores pedagógicos e, com isso, dos professores da Educação Infantil. Neste período, ainda não havia um documento atualizado que orientasse o Currículo e as práticas pedagógicas nos Centros Municipais de Educação Infantil (CMEI) pertencentes à Rede Municipal de Ensino de Ji-Paraná.

Ao visitar as escolas e observar os espaços e os cadernos de atividades das crianças é possivel compreender que as práticas pedagógicas expressavam a preocupação docente em alfabetizar por meio de atividades estereotipadas, letras com rostinhos, sentimentos e até com membros superiores e inferiores do corpo humano, letras soltas para as crianças pintarem ou fazerem colagens totalmente fora do contexto real e social; de memorização, como atividades em que a criança precisa 
escrever várias vezes a mesma letra ou número, muitas atividades retiradas da internet que não apresentavam ligação com o currículo e não representavam desafios para as crianças; pinturas de desenhos prontos, muitas vezes pintados por todas as crianças usando a mesma cor, sem nenhuma subjetividade; tracejados desenhos, letras ou números tracejados para cobrir. Ao mesmo tempo constatava-se a ausência da brincadeira, da imaginação e de espaços pensados para a infância, como demonstra a imagem a seguir:

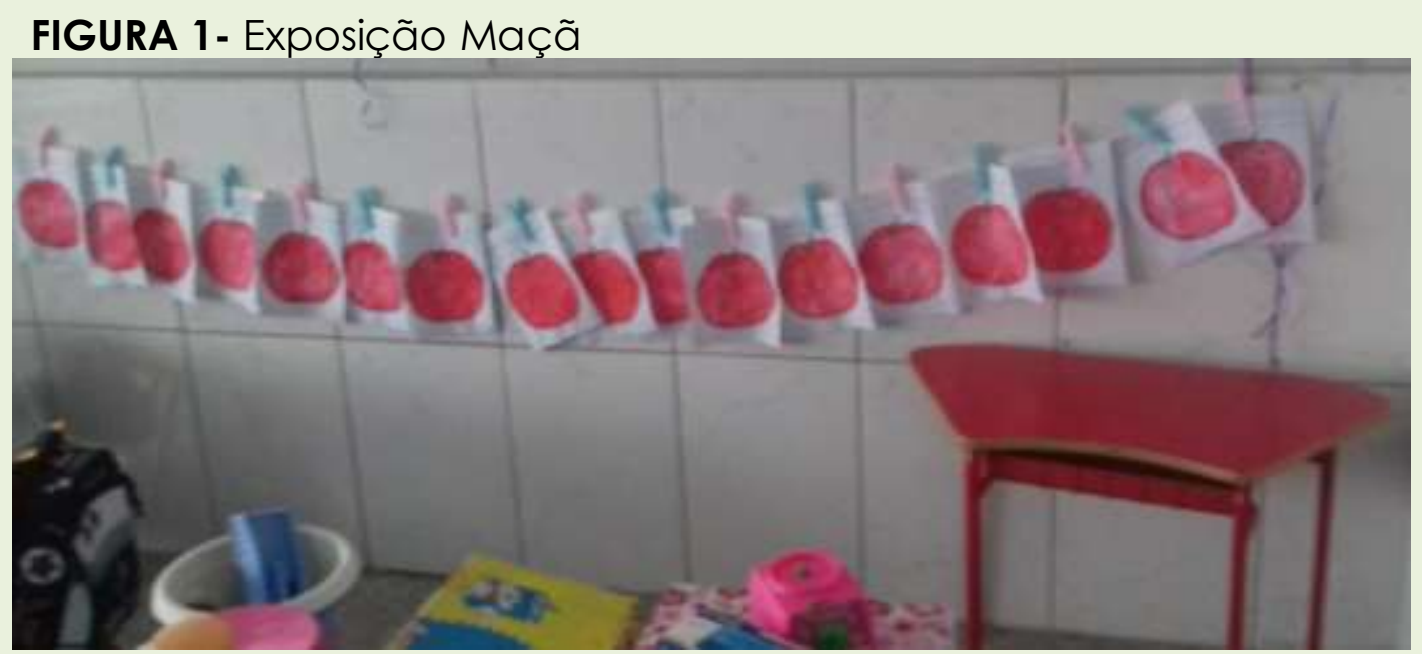

Fonte: Arquivos das pesquisadoras, 2015.

Para pensar sobre estas questões, inicialmente a aposta de formação da Secretaria Municipal de Educação (SEMED) foi a de reunir todos os professores dos Centros Municipais de Educação Infantil uma vez por bimestre para ofertar palestras e oficinas para um quantitativo de 102 (cento e dois) professores no total. No momento de palestras/oficinas era comum ver professores desinteressados, discordando das questões apresentadas, nas avaliações reclamavam que as formações sempre apresentavam o mesmo formato, que já conheciam toda pauta do encontro e que os mesmos não representavam novidades.

O modelo de formação supracitado estava pautado em uma estratégia técnico-academicista que, segundo Scarpa (1998) é conhecida por ser centrada em modelos. Percebe-se então, que este formato não 
atenderia de forma eficaz, pois, conforme Alarcão (2001), não é com a experiência que se aprende, mas com a reflexão sistemática sobre a experiência, isto é, o conhecimento prático desarticulado de uma reflexão organizada sobre suas diferentes implicações perde seu valor de busca, criação e contraste crítico para ser fonte de repetição e conservadorismo.

Ao realizar a avaliação das formações que vinham sendo realizadas pela rede municipal com os professores, percebe-se que apesar de gerar certo desconforto entre os professores em relação a suas práticas pedagógicas, mudanças significativas não aconteceram.

Esse processo de avaliação e reflexão sobre o trabalho de formação realizado fez com que se percebesse que seria necessário repensar o tipo de formação que estava sendo ofertado, admitir que a formação com base em modelos a ser reproduzidos só reforçariam as práticas docentes, muitas vezes inadequadas, mas já cristalizadas.

A partir disso, algumas questões surgiram e foram importantes para 0 repensar das ações que já vinham sendo realizadas: que tipo de formação é capaz de redimensionar a prática pedagógica? Como é possível pensar a formação a partir do contexto de cada grupo? E como acompanhar o crescimento pedagógico de cada grupo? Todas essas questões nos inquietavam enquanto formadoras.

Foi nesse contexto de inquietações e pela necessidade de repensar um modelo de formação que pudesse redimensionar a prática docente que no ano de 2015 elaboramos o projeto de formação continuada para os coordenadores pedagógicos uma vez que esses profissionais têm elementos e condição de atender um número maior de professores.

Com inspiração em Regina Scarpa a partir da leitura do livro Era assim, agora não... uma proposta de formação de professores leigos (1998), onde faz reflexões sobre os modelos de formação e estratégias formativas, a equipe formadora compreendeu que apenas uma formação reflexiva e focada na realidade de cada espaço escolar responderia de forma mais eficiente e assim, investimos na formação focada na figura do coordenar pedagógico. 
As melhores soluções muitas vezes não aparecem a priori ou de forma imediata, elas precisam ser construídas. Assim, erro e acerto são formas de investigação que expressam as vicissitudes do processo pedagógico quando este pode acontecer num contexto de autonomia e cooperação (SCARPA, 1998, p. 47).

Desta forma, compreendendo a individualidade de cada CMEI como possibilidade de reflexão sobre as suas próprias práticas pedagógicas, o projeto de Extensão da Universidade Federal de Rondônia, em parceria com a Secretaria Municipal de Educação, visualizou o coordenador pedagógico como o profissional estratégico para garantir uma formação continuada dos professores que atuam na Educação Infantil, sendo este entendido como o parceiro mais experiente do professor, aquele que está corresponsável pela aprendizagem, observa de perto as necessidades específicas de cada docente e tem condição de pensar a formação para a equipe.

O projeto previa as seguintes etapas: momentos de leitura com 0 objetivo de embasamento teórico da prática; momentos de roda de conversas onde cada coordenador apresentava suas angústias em relação ao planejamento docente, avaliação, registros, organização dos espaços, queixas dos docentes; momentos que consistiam em apresentar para 0 grupo de coordenadores algumas estratégias formativas que poderiam ser utilizadas por eles, além da socialização das experiências exitosas. Os encontros aconteciam mensalmente, com um grupo de quatorze coordenadoras, e o desafio principal de cada coordenadora era o de concretizar em ações práticas as Orientações Curriculares para a Educação Infantil do município.

A convicção era a de que o coordenador pedagógico deveria, por meio dos estudos e reflexões, pensar o cotidiano do trabalho desenvolvido nas escolas de Educação Infantil que atua e também refletir sobre seu papel na formação continuada dos professores.

O texto que segue apresenta algumas ações formativas desenvolvidas com os Coordenadores Pedagógicos, apontando alguns avanços em que se destacam os seguintes: atribuições do coordenador pedagógico, práticas 
pedagógicas, avaliação, planejamento e espaços, e também os desafios desta formação.

\section{AS CONTRIBUIÇÕES DO PROJETO DE FORMAÇÃO PARA AS PRÁTICAS PEDAGÓGICAS}

A formação continuada, inerente ao trabalho docente, deve fazer parte do dia a dia de todos os profissionais da educação e neste contexto queremos apontar algumas contribuições deste projeto de formação, bem como os desafios que ainda estão postos.

Durante os encontros buscou-se tratar das atribuições do coordenador pedagógico e foi possivel constatar que em algumas instituições esse profissional desempenhava muitos papéis, como se pode perceber nos relatos a seguir. Ao questionar como o grupo enxergava o papel do coordenador pedagógico, uma das coordenadoras, ao responder ao questionário aplicado a todos, disse que "Vê como um 'super visor', aquele que faz de tudo um pouco, e por fazer de tudo um pouco acaba por não fazer o seu trabalho direito" (Coordenadora pedagógica, 2015).

Pedimos a elas que descrevessem sua rotina diária de trabalho e nesse aspecto e outra coordenadora fez a seguinte descrição das atividades desenvolvidas por ela diariamente:

Planejamento diário com professores, atendimento aos alunos com dificuldades, atendimento aos pais, apoio as professoras quanto as dificuldades que acontece dentro de sala de aula ex: (criança que chora muito, que esporadicamente faz suas necessidades dentro da sala etc), acompanhamento nas realizações dos projetos, e apagando incêndio quando necessário (Coordenadora pedagógica, 2015).

Estes registros demonstram algumas confusões quanto ao seu papel, revelando que os acontecimentos diários da instituição organizavam o trabalho, resultando a falta de compreensão do grupo sobre as o papel e a atribuição do coordenador pedagógico dentro de um Centro Municipal de Educação Infantil. 
Avaliamos que havia um sentimento de falta de reconhecimento do papel desse profissional por parte dos demais funcionários da escola, uma sensação de cumprir muitos papéis, como resolver conflitos entre alunos e alunos, atender queixa dos pais, controlar o material pedagógico, ajudar o professor, preparar murais ao mesmo tempo ter a sensação de trabalho não finalizado. Entendemos assim que este profissional não tinha formado ainda sua identidade profissional, pois ao mesmo tempo em que se compromete com muitas questões na escola não tinha o reconhecido do grupo.

Nas rodas de conversas eram presentes preocupações, tais como: É correto o coordenador substituir professor? Coordenador pode assumir atividades como dar banho nas crianças? Quem deve organizar e controlar a entrega de materiais pedagógicos?

A estratégia utilizada para responder a estas questões sobre o papel do coordenador pedagógico foi leitura de textos para refletir sobre os desafios deste profissional, rodas de conversas, planejamento da rotina diária do coordenador, momento para que expusessem suas experiências exitosas com o grupo, configurando troca de experiências. Com isso puderam enxergar uma nas outras, elementos que as uniam enquanto profissionais. Estas ações permitiram com que elas não se sentissem solitárias nesta caminhada, formando uma rede de ajuda mútua.

Alguns instrumentos para organizar 0 trabalho foram sendo incorporados, tais como: inserir no calendário a data dos encontros de formação, uma tabela sobre quais aspectos observar no planejamento docente, observações sobre os espaços internos e externos da escola e sala de aula, organização da sala de aula, dos espaços para oportunizar as brincadeiras. Todas essas observações deveriam ser fonte de pesquisa e elementos para os encontros de formação continuada em serviço.

Superadas tais questões era momento de refletirmos sobre as práticas pedagógicas presentes na escola e confrontá-las com o Currículo da Educação Infantil, bem como o Referencial Curricular Nacional para a Educação Infantil, as Diretrizes Curriculares Nacionais para a Educação 
infantil, e desta forma traçar estratégias para redimensionar a prática pedagógica na direção de todos estes documentos orientadores.

A primeira questão colocada em pauta foi a necessidade de repensar a avaliação na Educação Infantil. Conforme dados levantados junto aos coordenadores pedagógicos, a rede municipal utilizava como instrumento de avaliação uma ficha individual com uma lista de conteúdos onde o professor marcava um "X" para apontar o conhecimento alcançado pelas crianças da educação infantil. Porém, o que se percebeu é que havia uma insatisfação por parte dos CMEls com o uso desse instrumento. A partir disso foi planejado ações que se voltassem para o estudo dessa questão.

Foi realizado o estudo do Livro de Jussara Hoffman Avaliação e Educação Infantil: um olhar sensivel e reflexivo sobre a criança (2012). Na obra, a autora aponta a avaliação na educação infantil como um conjunto de procedimentos didáticos que se estendem por um longo tempo e em vários espaços escolares, de caráter processual visando, sempre, a melhoria do objeto avaliado (HOFFMANN, 2012, p. 13). A autora chama a atenção para a importância da avaliação e sua função de redimensionar a prática pedagógica.

A partir das leituras e das discussões suscitadas no decorrer dos estudos sobre avaliação, alguns termos como avaliação mediadora, caráter processual, observação, registros entre outros foram ganhando sentido para as coordenadoras que tiveram elementos e segurança para realizar a discussão na escola.

Nesse movimento foi possível repensar coletivamente a forma de avaliar as crianças da Educação Infantil, definir um novo instrumento de avaliação, com a clareza de que só a mudança do instrumento não garantiria a avaliação, mas que esta deveria ocorrer acompanhada com uma nova visão e função da avaliação para a Educação Infantil.

Segundo Hoffmann (2012), a avaliação mediadora tem como características a observação individualizada da criança, a ação reflexiva sobre os diversos comportamentos do educando, o planejamento como forma intencional de propor atividades significativas. 
Os estudos sobre a avaliação trouxeram a necessidade de repensar o planejamento, pois a avaliação só faz sentido se as atividades propostas forem pensadas adequadamente para a idade, valorizando os desafios possíveis para as crianças, permitindo o envolvimento das crianças, bem como valorizando todos os campos de experiências no planejamento, visto que a ênfase estava nas atividades de linguagem oral, escrita e matemática, enquanto os outros campos não tinham visibilidade no planejamento docente.

Schimtt (2006) chama a atenção para o planejamento não ser apenas burocrático, mas pautado no interesse e curiosidade das crianças, realizado com o entendimento de que é um instrumento importante para o professor e reflete sua visão de mundo e concepções a respeito da educação infantil.

O objetivo principal do planejamento é possibilitar um trabalho mais significativo e transformador na sala de aula, na escola e na sociedade. O plano escrito é o produto destes processos de reflexão e decisão. Não deve ser feito por uma exigência burocrática, mas, ao contrário, deve corresponder a um projeto compromisso do professor, tendo, pois, suas marcas (SCHIMTT, 2006, p. 2).

Na tentativa de buscar caminhos para as angústias ligadas ao planejamento, voltadas ao "como fazer", organizamos com as coordenadoras pedagógicas quatro encontros para estudos sobre a temática que, além da discussão teórica, tiveram momentos para fazer a análise de atividades propostas para as crianças e como eram organizadas dentro do planejamento docente.

Em visitas realizadas às instituições, foram encontradas atividades nas escolas que não apresentavam desafios, desconsiderava as singularidades das crianças, além de serem focadas em atividades de prontidão e memorização, em desacordo com o currículo proposto para a Educação Infantil.

A idéia de prontidão para a alfabetização está presente em várias práticas. Por um lado, há uma crença de que o desenvolvimento de determinadas habilidades motoras necessárias para aprender a ler e escrever, é resultado da maturação biológica, havendo nesse caso pouca influência externa (BRASIL, 1998, p.119). 
Neste caminho de memorização e atividades sem uma função significativa para as crianças, analisamos as atividades do campo de experiência matemática; fazendo alguns questionamentos: como se formam os conhecimentos matemáticos? Como se constrói a coordenação motora fina e a coordenação motora ampla? Entre outros.

A crença era de que para a criança aprender matemática deveria trabalhar número por número, relacionar quantidades ao numeral, que para escrever era necessário primeiro aprender a coordenação motora fina ao cobrir tracejados, e essa lógica de apresentar primeiro a parte para depois o todo seguia para os demais campos de experiências, como se pode constatar nas imagens de atividades apresentadas a seguir:

FIGURA 2: Atividade matemática

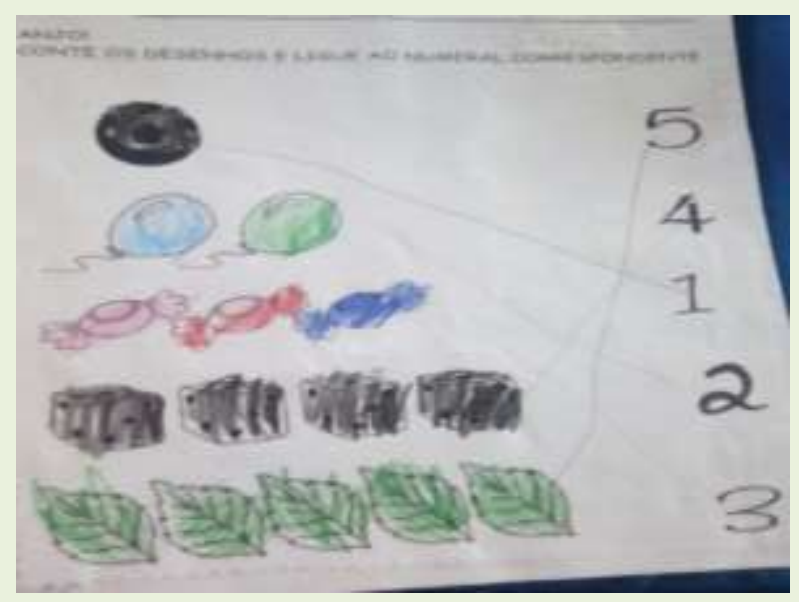

Fonte: Arquivo das pesquisadoras, 2015.

FIGURA 3: Figura com pontilhado

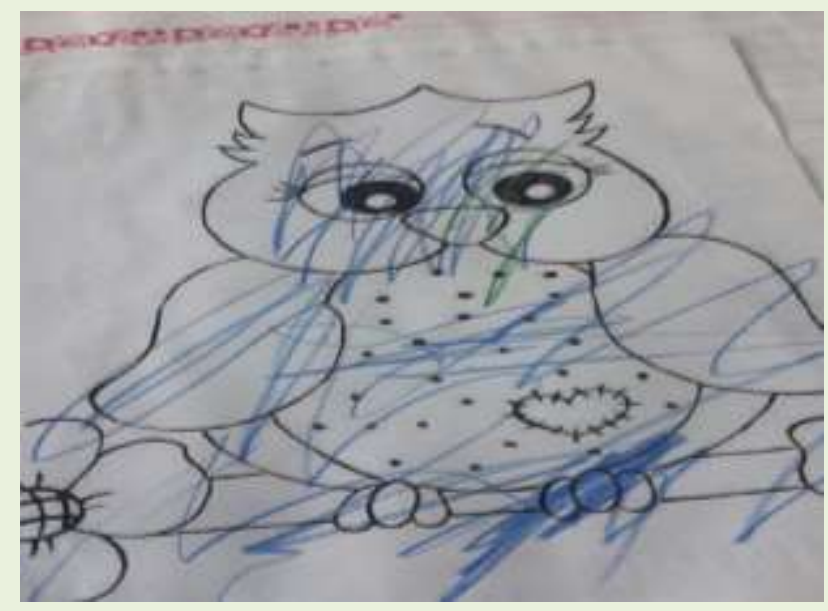

Fonte: Arquivo das pesquisadoras, 2015. 
A formação com as coordenadoras buscou questionar tais atividades à luz de referenciais que pautam o uso real e social em situações em que seja necessário o uso da escrita, da leitura, da oralidade bem como de outros campos de experiências, valorizando as interações e brincadeiras, como podemos perceber nas imagens que seguem:

FIGURA 4: Jogo de tabuleiro

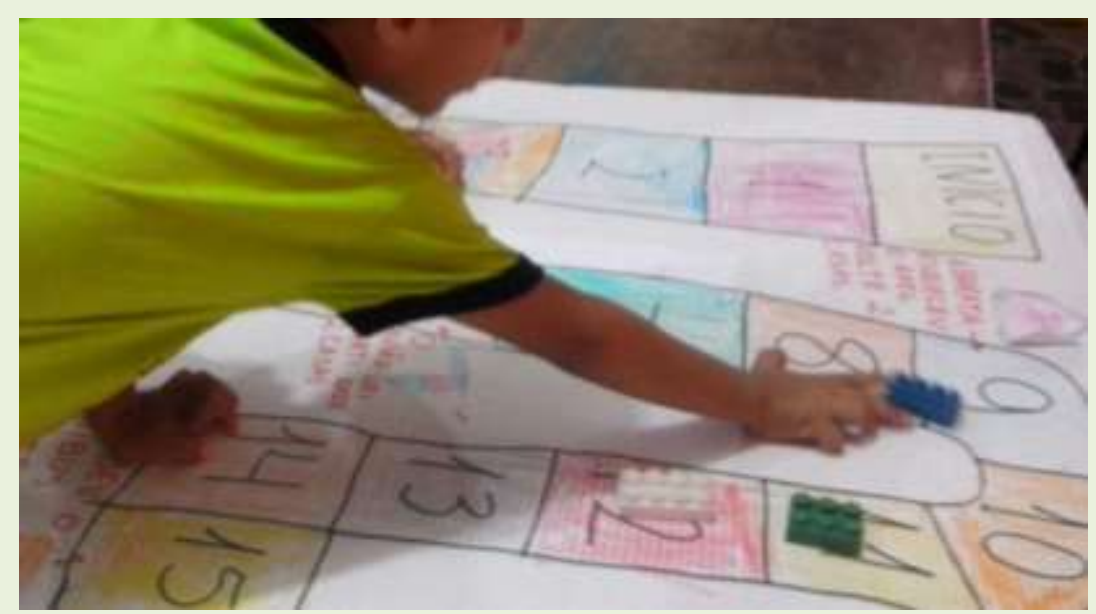

Fonte: Arquivo das pesquisadoras, 2017.

FIGURA 5: Manipulando massa de biscoito

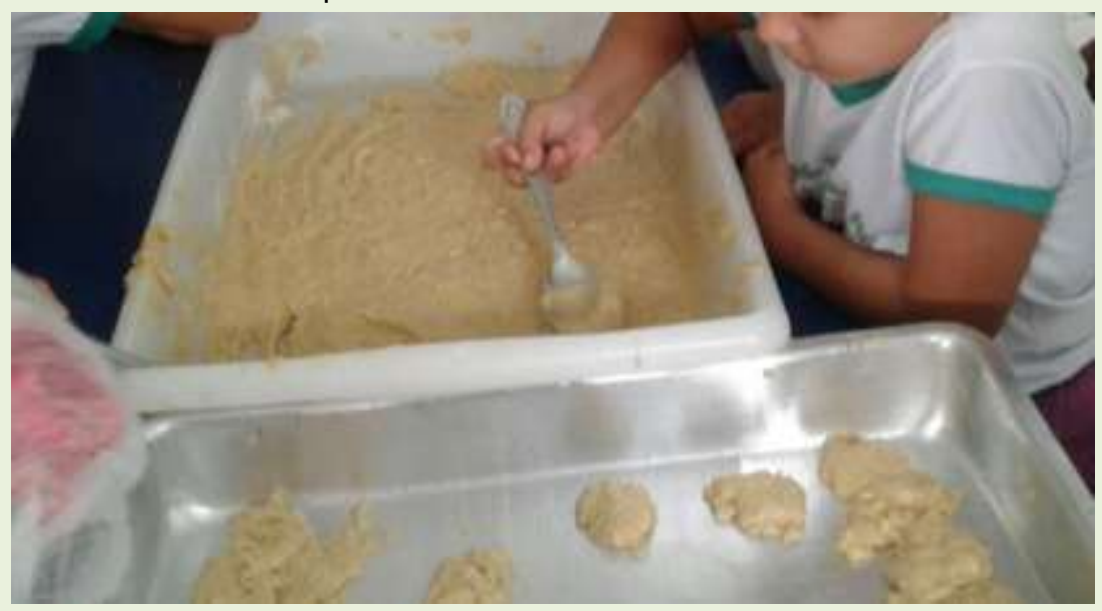

Fonte: Arquivo das pesquisadoras, 2015.

O objetivo da análise das atividades foi para que elas pudessem compreender que os conceitos matemáticos são construídos pela criança por meio de jogos, brincadeiras, na experimentação, na resolução de problemas, e assim compreender que na manipulação dos mais variados 
objetos, texturas e no movimento corporal de forma geral é que se desenvolve a coordenação motora.

Esses momentos de estudos e reflexões sobre o cotidiano das escolas de Educação Infantil tinham como principal objetivo oportunizar conhecimentos, elementos, argumentos e estratégias para que pudessem questionar as práticas recorrentes e pensar outras possibilidades de organizar o planejamento com os docentes.

A partir desses momentos de reflexões e estudos, as professoras passaram a utilizar as modalidades organizativas do planejamento (sequência didática, projetos e atividades permanentes), superando as propostas de atividades soltas, ampliando oferta de atividades desafiadoras. Os demais campos de experiências passaram a ser contemplados no planejamento docente, de forma intercalada e sequenciada, fazendo sentindo para a criança pequena.

O planejamento pedagógico na Educação Infantil precisa ser discutido e articulado aos sujeitos que estão inseridos nestes ambientes coletivos de educação, assim é imprescindível trazer para a sala de aula, através dos planejamentos, as manifestações que as crianças expressam no seu dia-a-dia, a partir de seus balbucios, choros, falas, gestos, desejos, hipóteses e conhecimentos prévios, estes são de suma relevância para um trabalho que respeite as culturas infantis (AHMAD, 2011, p. 4).

Nesta perspectiva a criança passa a ser o foco do planejamento e as atividades estereotipadas são gradativamente superadas, além de todos os campos de experiências serem contemplados no planejamento.

FIGURA 6: Oficina de proposta

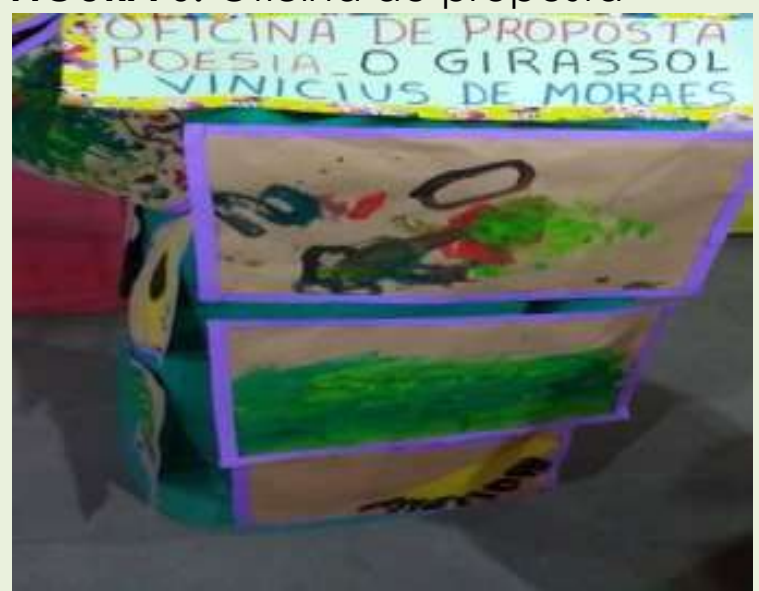

Fonte: Arquivo das pesquisadoras, 2015. 
FIGURA 7 - Identificação na porta da sala

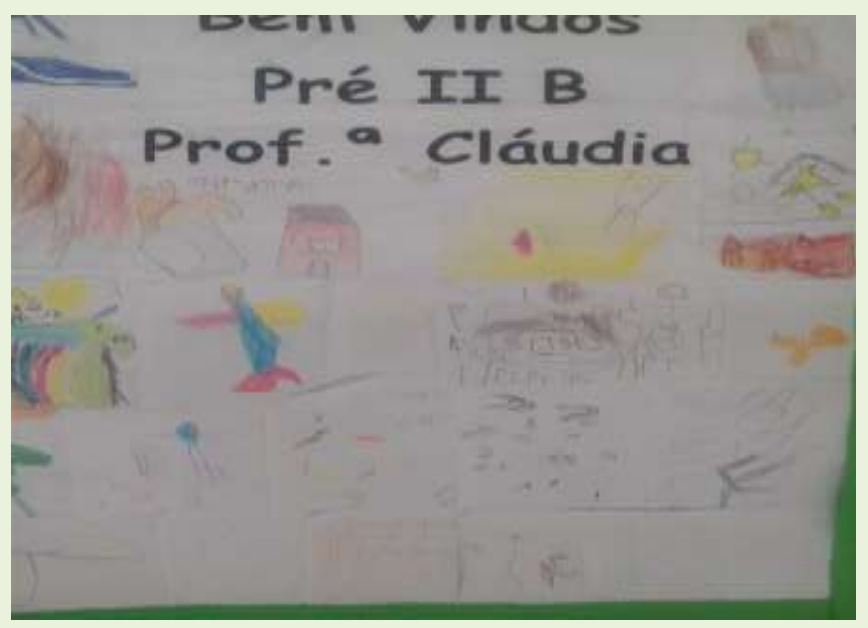

Fonte: Arquivo das pesquisadoras, 2017.

Nesse contexto, também revelaram-se como possibilidade os espaços ambientados (cantos temáticos), que passaram a compor as salas de aula. Para Horn (2004), a organização do espaço em cantos temáticos possibilita um entendimento de uso compartilhado, onde, ao mesmo tempo, são possiveis escolhas individuais e coletivas, que favorecem a autonomia das crianças. Nestes espaços as crianças brincam, criam enredos sem a intervenção do adulto, incentivando o protagonismo infantil.

Os espaços externos também são pensados com a finalidade de proporcionar a imaginação e a brincadeira, permitindo às crianças pequenas se colocarem como atores e atrizes nos mais variados papéis da sociedade.

Os espaços ambientados ainda rendem algumas tensões, como preocupações na gestão do tempo em que serão utilizados, ou mesmo como organizá-los de modo que seja atrativo para as crianças, a necessidade de renovação dos mesmos. No entanto, aos poucos se tornam concretos na maioria dos CMEls da rede estudada, como podemos ver nas imagens a seguir: 
FIGURA 8: Cantinho da beleza

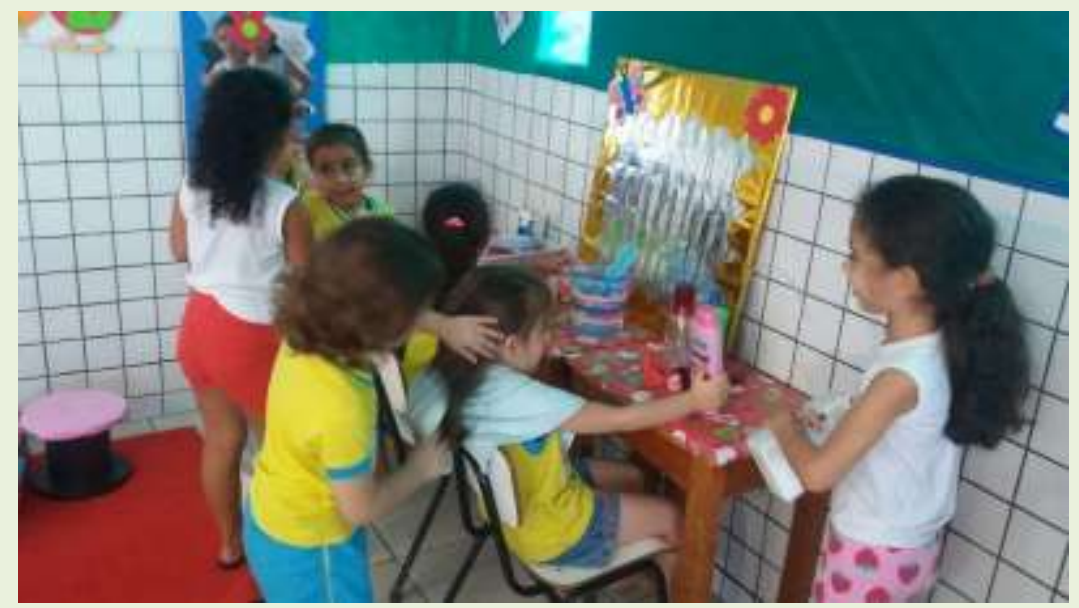

Fonte: Arquivo das pesquisadoras, 2017.

FIGURA 9: Espaço externo

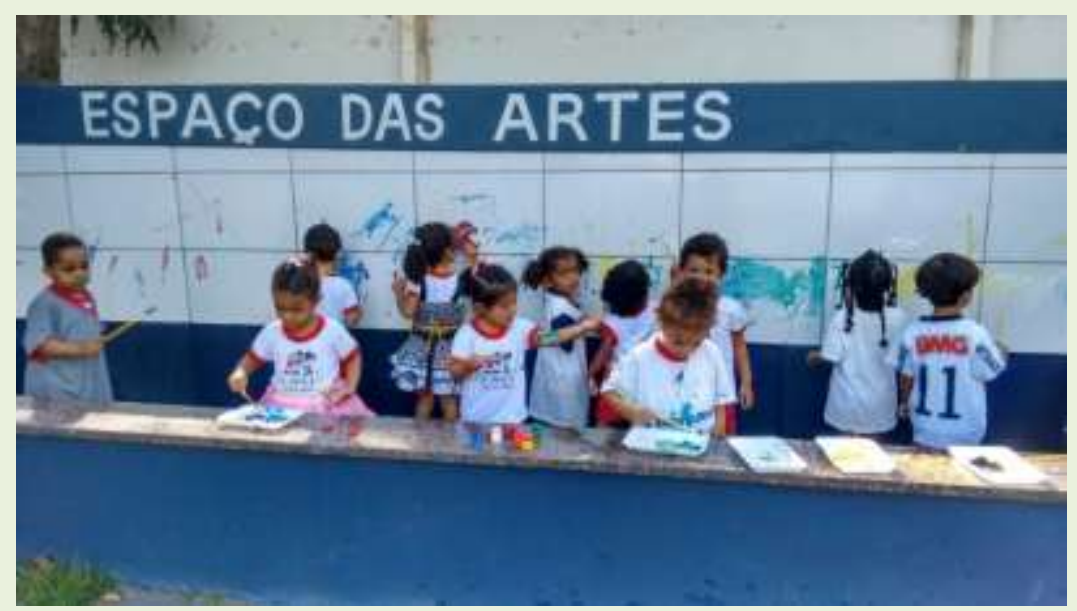

Fonte: Arquivo das pesquisadoras, 2017.

A leitura, a troca de experiência, a tematização da prática, o planejamento e a execução das ações convencem, pois demonstra de forma prática algo que antes parecia impossível.

A avaliação final do projeto de formação com as coordenadoras pedagógicas nos revelou a importância que representa a formação dos coordenadores pedagógicos da Educação Infantil. Percebemos, por meio dos relatos, que algumas coordenadoras, em especial as que participaram de todo o projeto de formação, estão fazendo uso do processo reflexivo sobre suas próprias práticas, como relata uma coordenadora: 
Ao fim desses anos de estudo faço a seguinte reflexão: o conhecimento realmente nos tira das trevas! Como esse projeto transformou minha ação como coordenadora pedagógica! Hoje consigo pensar nas necessidades do professor e quais ações necessárias para garantir que a formação transforme a sua prática. O processo de pensar, repensar, se tornou parte da minha competência profissional. Obrigada pelo cuidado conosco durante este período, continuem caminhando, sendo os parceiros mais experientes, cresci e aprendi muito (Coordenadora pedagógica, 2017).

Quando foram questionadas sobre os avanços da equipe, muitas questões emergiram, como o fato das professoras sentirem-se mais seguras ao desenvolverem as atividades com as crianças, ao planejar, considerando as crianças e suas especificidades, o fato de conseguir contemplar no planejamento todos os campos de experiências. Uma das coordenadoras destaca como avanço do grupo a "organização do tempo e do espaço, dar significância para todos os campos de experiência e pensar na criança". Esses três elementos apontados pela coordenadora são de extrema importância para garantir a qualidade pedagógica da escola, pois ao considerar a criança e suas especificidades a escola de modo geral oportunizará experiências significativas.

Pensando nos desafios que ainda estão postos e precisam ser superados, destacamos a falta de permanência dos coordenadores na formação. Durante a realização do projeto de formação ouve muitas trocas de coordenadoras, impossibilitando assim uma sequencia no avanço reflexivo de cada equipe de alguns dos Centros Municipais de Educação Infantil.

Alguns grupos não tiveram este profissional, e dos que iniciaram a formação apenas quatro finalizaram e nestes grupos é possível observar os avanços de forma mais significativa. Ao visitar as escolas é perceptível o engajamento do grupo de forma diferente, ou seja, todos caminham na direção de alcançar uma educação para a infância.

No entanto, os grupos que não contam com a figura do coordenador, ou aquele que teve muitas trocas compreende que existe um movimento de 
mudança na Educação Infantil, no entanto caminham a passos mais lentos, pois não teve no decorrer das formações um acompanhamento sistematizado como os demais. Isso se reflete ao observamos a organização do trabalho pedagógico na escola de atuação desses profissionais.

Ainda temos os desafios dos registros que não estão plenamente consolidados nas práticas das coordenadoras e das professoras, um instrumento de trabalho importante que permite além de registrar ações importantes do dia a dia é fonte de reflexão e pesquisa. A partir dos registros é possível perceber situações que necessitam de atenção. Com isso, o registro é fonte de estudo dentro dos grupos, pois eles revelam comportamentos, reflexões, angustias e o crescimento pessoal e reflexivo de cada profissional e do coletivo escolar.

Outro desafio necessário é garantir que cada coordenador possa construir seu Plano de Formação Continuada dentro das instituições. Esse plano de formação nesta etapa se faz necessário, pois consideramos que os grupos já possuem maturidade para compreender onde ainda precisam avançar. O Plano de formação representa um importante instrumento do trabalho da coordenação pedagógica.

\section{ALGUMAS CONSIDERAÇÕES}

O trabalho com crianças nesta faixa etária tem suas especificidades sendo necessário aos profissionais que atuam na etapa muito conhecimento a respeito das crianças e das infâncias. Estas precisam estar no centro do trabalho pedagógico.

Nesse sentido, o projeto de formação com as coordenadoras pedagógicas representa importante política de formação no município de Ji-Paraná, necessário para que as ações das coordenadoras possam ajudar a redimensionar a prática pedagógica nas escolas de Educação Infantil.

Foi possível compreender que os modelos de formação baseados nas reproduções não possibilitam ao professor autonomia de refletir sua prática, impossibilita o questionamento de sua realidade, passando a ser um mero técnico que apenas reproduz experiências. 
A parceria com a Universidade permitiu pensar a formação de forma colaborativa e contribuiu para que fosse possivel responder questões de cunho pedagógico e organizacional por duas instituições importantes: a escola e a universidade, de modo que ao mesmo tempo em que se analisou as práticas concretas também se fez reflexões em sintonia com as discussões acadêmicas e vice-versa.

De modo geral o projeto possibilitou a síntese de que as estratégias formativas elaboradas a partir da reflexão com o grupo permitem que seus integrantes olhem para si mesmos e nesta perspectiva professor e coordenador deixam de ser meros técnicos para serem pesquisadores. Com isso aprimoram suas práticas e ganham autonomia profissional. A escola representa este importante espaço de formação.

Com o desenvolvimento de um trabalho dessa natureza, as mudanças nas práticas começam a aparecer não de forma impositiva, mas por que a partir das leituras, discussões e reflexões os profissionais se convencem da importância do planejamento docente, do ato de avaliar, registrar, de considerar as especificidades da criança pequena, valorizando a brincadeira, as interações e as trocas entres pares, compreendendo que o cuidar e o educar são indissociáveis tendo a clareza de que todos os espaços da escola são pedagógicos portanto, devem ser pensados e planejados considerando a infância.

Deste modo o coordenador pedagógico, deve, por meio dos estudos e reflexões, pensar o cotidiano do trabalho desenvolvido nas escolas de Educação Infantil bem como refletir sobre seu papel na formação continuada dos professores.

As questões relacionadas a formação do coordenador pedagógico não se esgotam com as ações já realizadas, mas será importante que seja pensado um acompanhamento contínuo deste profissional, sendo necessário repensar o projeto de formação desenvolvido para que seja possível sua continuidade. 


\section{REFERÊNCIAS}

ALARCÃO, I. Escola reflexiva e nova racionalidade. Porto Alegre: Artes Médicas, 2001.

ABREU, L.C. BRUNO, E.B.G. O coordenador pedagógico e a questão do fracasso escolar. In: ALMEIDA, L. R., PLACCO, V.M.N. de S.O. Coordenador Pedagógico e questões da contemporaneidade. São Paulo: Edições Loyola, 2006.

AHMAD, L.A.S. Planejamento na Educação Infantil: uma construção mediada pela coordenação pedagógica no núcleo de Educação Infantil IPE Amarelo. Curitiba, PUC,2011.

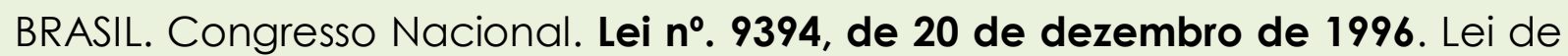
Diretrizes e Bases da Educação Nacional (LDBEN). Estabelece as diretrizes e bases da educação nacional. Brasília, DF, 1996.

BRASIL. Lei $n^{\circ}$ 13.257, de 8 de março de 2016. Dispõe sobre as políticas públicas para a primeira infância. Brasília, Planalto, 2016.

BRASIL. Conselho Nacional de Educação. Resolução CNE/CEB n 5/2009. Diretrizes Curriculares Nacionais para a Educação Infantil. Brasília, DF: Diário Oficial da União, 18 dez de 2009.

BRASIL. Ministério da Educação. Referencial Curricular Para a Educação Infantil. Vol. 1. Brasília: MEC/SEl, 1998.

BRASIL. Senado Federal. Emenda constitucional $n^{\circ} 59$ de 11 de novembro de 2009. Diário Oficial da União, Brasília, 12 de novembro de 2009.

FERREIRA, N.S.C. Supervisão Educacional: uma reflexão crítica. Petrópolis, Vozes, 16. ed., 2012.

HOFFMANN, J. Avaliação e educação infantil: um olhar sensivel e reflexivo sobre a criança. Porto Alegre: Mediação, 2012.

HORN, M.G.S. Sabores, cores, sons, Aromas: a organização dos espaços na educação infanti. Porto Alegre. Artmed,2004.

PIMENTA, S. G. Professor reflexivo: construindo uma crítica. In: PIMENTA, Selma Garrido; GHEDIN, Evandro (orgs). Professor Reflexivo no Brasil: gênese e crítica de um conceito. São Paulo: Cortez, 2007.

SAVIANI, D. História das Ideias Pedagógicas no Brasil. Campinas, SP: Autores Associados, 2010.

SCARPA, R. Era assim, agora não: uma proposta de formação de professores leigos. São Paulo: Casa do Psicólogo, 1998.

SCHMITT, A. Registro de Planejamento na Educação. Santa Catarina. Ed FURB. Vol. ol, n 2. 2006.

ZABALZA, M. A. Qualidade em educação infantil. Porto Alegre: ArtMed, 1998. $288 \mathrm{p}$. 
ZEICHNER, k. Para além da divisão entre professor-pesquisador e pesquisadoracadêmico. In: FIORENTINI, D; GERALDI, C.G e PEREIRA, E.M (orgs). Cartografias do trabalho docente. Campinas: mercado das letras, 1998.

Recebido em: Novembro de 2017 Aprovado em: Março de 2018 